\title{
X-linked bulbo-spinal neuronopathy: a family study of three patients
}

\author{
JONATHAN WILDE, TIM MOSS, DAVID THRUSH \\ From the Department of Neurology, Freedom Fields Hospital, Plymouth and the Department of \\ Neuropathology, Frenchay Hospital, Bristol, UK
}

SUMmaRY The clinical features of two brothers and one nephew with X-linked recessive bulbospinal neuronopathy are described. The neurophysiological investigations and sural nerve biopsy, previously unreported, confirmed that both motor and sensory nerves are affected. Because of the genetic implications, the importance is stressed of recognising this disorder as a separate entity which should not be classified with the spinal muscular atrophies.

In 1968, Kennedy and colleagues ${ }^{1}$ reported 11 males from two families with a distinct form of bulbar and spinal muscular atrophy which was slowly progressive and inherited as an X-linked recessive. Since then a further 31 patients have been described in five separate reports, ${ }^{2-6}$ ten being described by Harding and colleagues ${ }^{6}$ in 1982 . As well as reporting similar findings to Kennedy's, they found reduced or unrecordable sensory nerve action potentials in seven patients and because of this abnormality they named it X-linked recessive bulbo-spinal neuronopathy.

$\mathrm{X}$-linked recessive bulbo-spinal neuronopathy is a slowly progressive disorder which develops between the third and fifth decades. Muscle wasting and weakness, which is often preceded by cramps for many years, commonly starts proximally in the limbs and then progresses to involve the masticatory, facial and bulbar musculature. Distal wasting and weakness occurs more commonly in the arms. Fasciculations are prominent in the peri-oral region and tongue as well as being generalised. Tendon areflexia is invariable at an advanced stage. A fine tremor of the outstretched hands may predate the onset of muscle weakness, gynaecomastia is a common finding and there is an increased incidence of diabetes mellitus, both in affected patients and in their first degree relatives. Patients have a normal life expectancy.

We report three patients with this disorder (fig 1),

Address for reprint requests: Dr D Thrush, Plymouth General Hospital, Department of Neurology. Freedom Fields, Plymouth PL4 7JJ, UK.

Received 25 November 1985 and in revised form 24 June 1986. Accepted 25 June 1986 together with their neurophysiological findings and the results of a muscle and sural nerve biopsy taken from one. Nerve histology has not been previously described.

\section{Case reports}

112 , a 70 year old retired dockyard statistician, had a long history of hand tremor and intermittent episodes of bronchial asthma; he was otherwise well until the age of 58 , when he developed difficulty climbing stairs, and soon after became aware of weakness in his arms and hands. When 65 , he noticed progressive slurring of speech, difficulty with mastication and ankle weakness. At present he is unable to get up from a low chair, finds walking up stairs difficult and can no longer chew or swallow solid food. On examination, he was dysarthric and had wasting and weakness of the muscles of mastication and the face with peri-oral fasciculations. There was diminished palatal and pharyngeal movement and wasting, weakness and fasciculations in the tongue. He had global wasting and weakness in the arms and legs with widespread fasciculations. All tendon reflexes were absent. Sensory testing was normal. He had a fine tremor of the outstretched hands and gynaecomastia.

II 4, a 66 year old retired engineering instructor, developed muscle cramps in his thighs and forearms and a tremor of both hands in his early thirties. At the age of 47 he developed difficulty climbing stairs and when 54 he became aware of progressive arm weakness and later developed weakness and wasting of the hand muscles. When 61 , he noticed that his speech was becoming slurred and he had difficulty swallowing. At present he is still able to walk unaided but finds walking up stairs difficult. He is unable to cope with dextrous tasks and has to concentrate when swallowing fluids. On examination he was dysarthric and had wasting and weakness of the muscles of mastication, an asymmetrical facial weakness and wasting and weakness of his tongue. $\mathrm{He}$ had peri-oral and tongue fasciculations and diminished pal- 


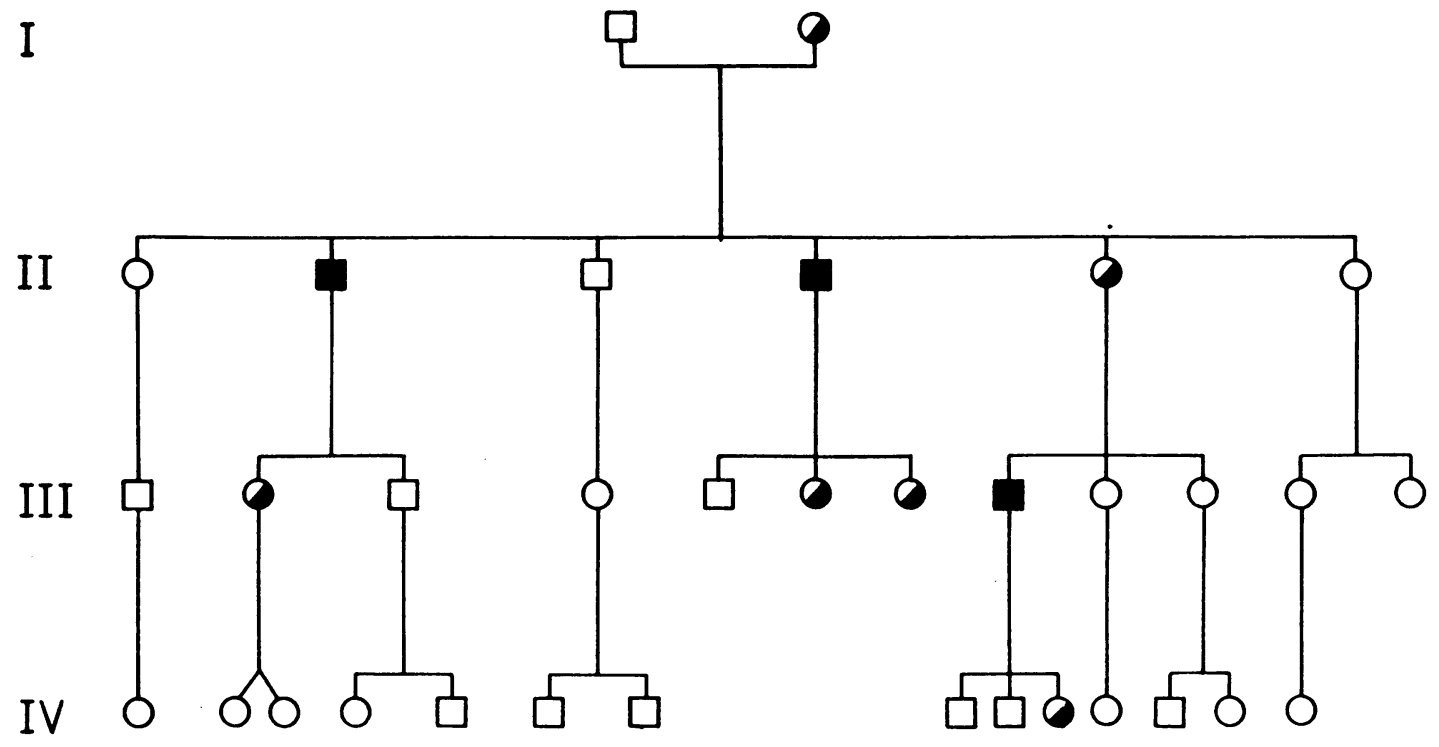

Fig 1 Family pedigree. $\square$ Affected members, O Obligate carriers.

atal and pharyngeal movement. There was wasting, weakness and fasciculations of the arms and of the small muscles of both hands. He had bilateral proximal wasting, weakness and fasciculations in the legs, the right thigh being more affected than the left. All tendon reflexes were absent. Sensory testing was normal. He had a fine tremor of the outstretched hands, gynaecomastia and an exaggerated lumbar lordosis.

III 8 , aged 42 years, was seen during the screening of the asymptomatic members of the family. He admitted that he had occasional cramps in both legs and also he had noticed fasciculations in all four limbs for several years, but he was not aware of any weakness, nor of any difficulty swallowing

Table 1 Creatine kinase levels (normal range 24-170 units)

\begin{tabular}{lccccc}
\hline Affected & & \multicolumn{2}{c}{ Obligate carrier } & \multicolumn{2}{c}{ Possible carrier } \\
\hline$I I_{2}$ & 688 & $I I_{5}$ & 105 & $I I_{1}$ & 105 \\
$I I_{4}$ & 1500 & $I I I_{2}$ & 110 & $I I_{6}$ & 92 \\
$I I I_{8}$ & 1033 & $I I I_{6}$ & 193 & $I I I_{9}$ & 108 \\
& & $I I I_{7}$ & 117 & $I I I_{10}$ & 178 \\
& & & & $I I I_{11}$ & 89 \\
& & & & $I I I_{12}$ & 73 \\
\hline
\end{tabular}

or talking. On examination there were coarse fasciculations affecting the face, tongue, sternomastoids and proximal muscles in both the upper and lower limbs. There was wasting of the tongue, but there was otherwise no abnormality in the cranial nerves. There was mild wasting of the biceps and triceps muscles, there was diffuse weakness in the upper limbs which was more marked proximally, but strength in the lower limbs was normal. The tendon reflexes were present with reinforcement and apart from minimal loss of vibration sensation at the ankles, there was no sensory deficit.

\section{Investigations}

Routine blood count, urea and electrolytes and fasting blood sugar were normal. Electrocardiograms showed no evidence of a conduction abnormality although this has been reported in previous patients. ${ }^{4}$ The results of the creatine kinase levels are shown in table 1. All three patients had elevated creatine kinase levels, which is a consistent finding in this disorder. Usually this enzyme does not rise to such high levels in the spinal muscular atrophies or in motor neuron disease and is thus a useful diagnostic indicator. Only

Table 2 Nerve conduction studies

\begin{tabular}{|c|c|c|c|c|c|c|}
\hline & \multicolumn{3}{|c|}{ Motor nerve conduction velocities $(\mathrm{m} / \mathrm{s})$} & \multicolumn{3}{|c|}{ Sensory nerve action potential amplitude $(\mu \mathrm{V})$} \\
\hline & Median & Ulnar & $\begin{array}{l}\text { Lateral } \\
\text { popliteal }\end{array}$ & Median & Ulnar & Sural \\
\hline $\begin{array}{l}I I_{2} \\
\text { Distal latency }(\mathrm{m} / \mathrm{s}) \\
I_{4} \\
\text { Distal latency }(\mathrm{m} / \mathrm{s})\end{array}$ & $\begin{array}{l}37 \\
7 \cdot 2 \\
-\end{array}$ & $\begin{array}{l}48 \\
3 \cdot 3 \\
-\end{array}$ & $\begin{array}{c}45 \\
7 \cdot 3 \\
49 \\
6 \cdot 1\end{array}$ & $\begin{array}{l}9 \\
\text { Absent }\end{array}$ & $\begin{array}{l}3 \\
\text { Absent }\end{array}$ & $\begin{array}{l}\text { Absent } \\
\text { Absent }\end{array}$ \\
\hline
\end{tabular}




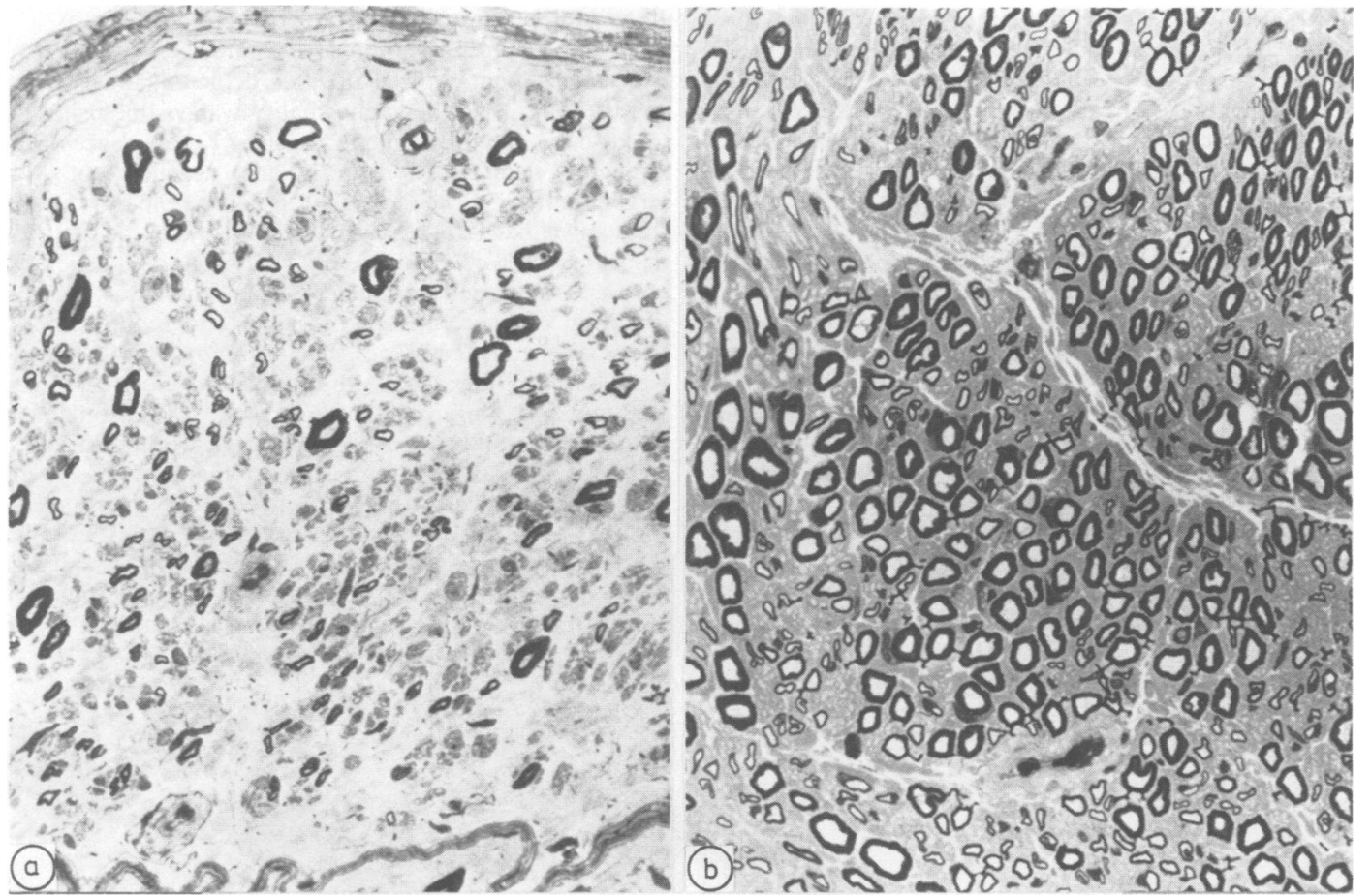

Fig 2 (a) Semi-thin (I $\mu \mathrm{m})$, resin-embedded, transverse section of part of a nerve fascicle from the sural nerve biopsy, from patient II 4, showing obvious depletion of larger sized myelinated fibres ( $\times 500$, Toluidine Blue stain). (b) Similar preparation showing a fascicle from a normal sural nerve, for comparison ( $\times 500$, Toluidine Blue stain).

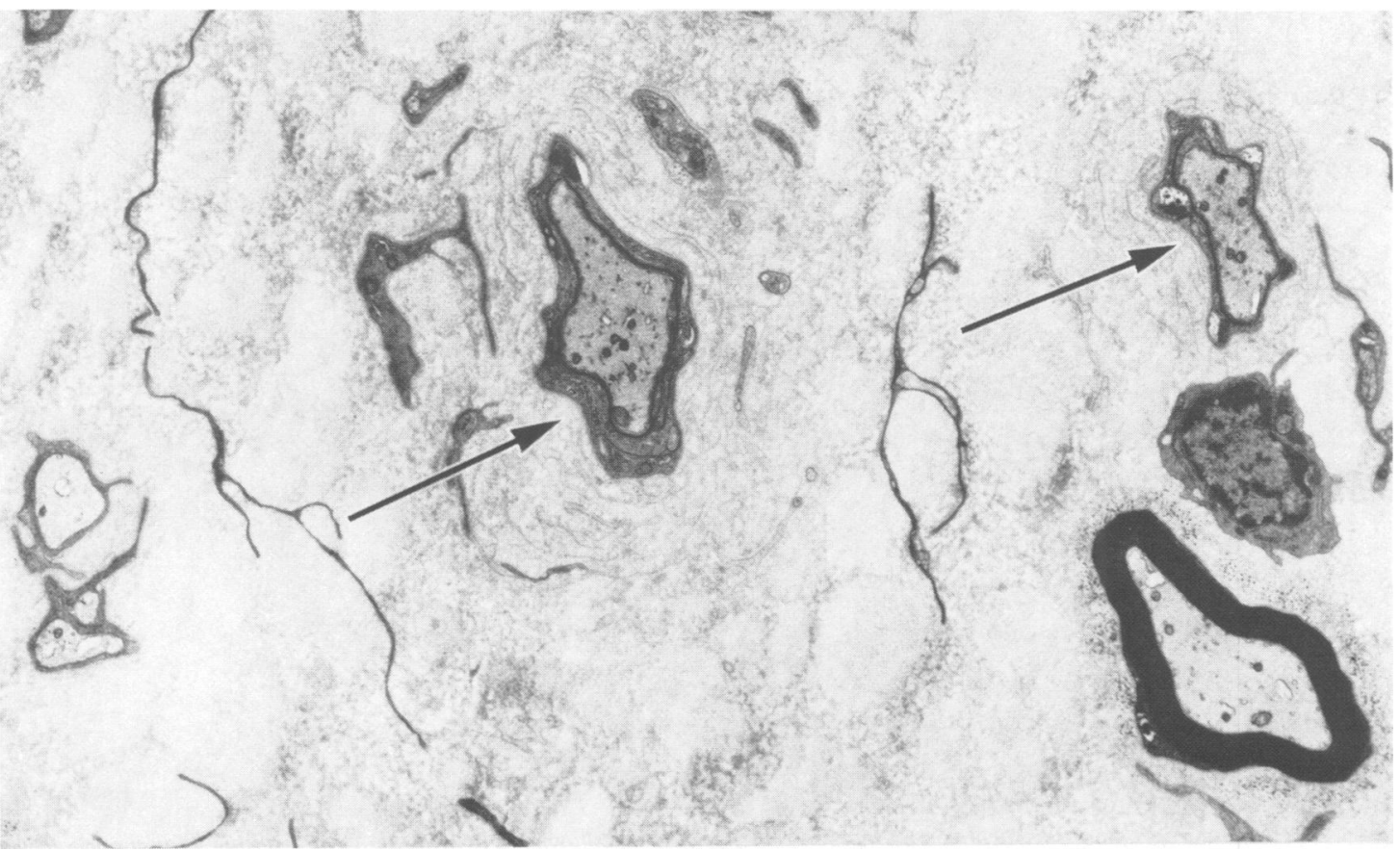

Fig 3 Electron micrograph of the sural nerve biopsy specimen (case 2) showing fibre depletion and increased endoneurial collagen. Tw'o axons appear inappropriately thinly myelinated (arrows), and there is reduplication of basement membrane around their associated Schwann cell cytoplasm. $\times 6300$. 
one of the obligate carriers had an elevated creatine kinase level and III 10, the daughter of an obligate carrier, had a level of the upper limit of normal suggesting the possibility that she may be a carrier. In two patients described by Schoenen and colleagues ${ }^{5}$ plasma testosterone levels were below normal and 17b-oestradial levels elevated, possibly explaining their gynaecomastia. In II 4 these hormone levels were normal.

The results of nerve conduction studies are shown in table 2. All sensory nerve action potentials were reduced or absent. There were prolonged terminal latencies throughout motor nerve testing, although motor conduction velocity was preserved.

The biopsy of the quadriceps muscle from II 4 showed severe and longstanding denervation atrophy of motor unit type with many large groups of fibres almost entirely reduced to pyknotic nuclear clumps. There was also evidence of continuing denervation, with remaining fibre groups showing widespread variation of fibre size and scattered small angulated fibres. In addition, some myopathic changes were observed, including numerous central nuclei in larger diameter fibres, scattered basophilic regenerating fibres and occasional fibres undergoing phagocytosis.

Histological examination of the sural nerve biopsy from the same patient showed obvious depletion of myelinated fibres (fig 2). No other abnormality was visible using light microscopy, but ultrastructurally there was evidence of both segmental demyelination and axonal degeneration. Many larger diameter axons lacked myelin or were inappropriately thinly myelinated, often with myelin debris in the associated Schwann cell cytoplasm, and there was a generalised increase in endoneurial collagen (fig 3). There was some proliferation of Schwann cell processes and reduplication of their basement membranes, but no onion bulb formations were found. Other axons appeared degenerate, with focal swelling and abnormal accumulation of neurofilaments, mitochondria and irregular membranous profiles (fig 4).

Teased fibre preparations showed changes of segmental demyelination, with thinly re-myelinated internodes or shorter intercallated segments in several fibres examined (fig 5). No Wallerian-type degeneration was seen, but some fibres showed evidence of distal axonal regeneration, with abrupt transition along the fibre from normal length internodes to uniformly much shorter ones.

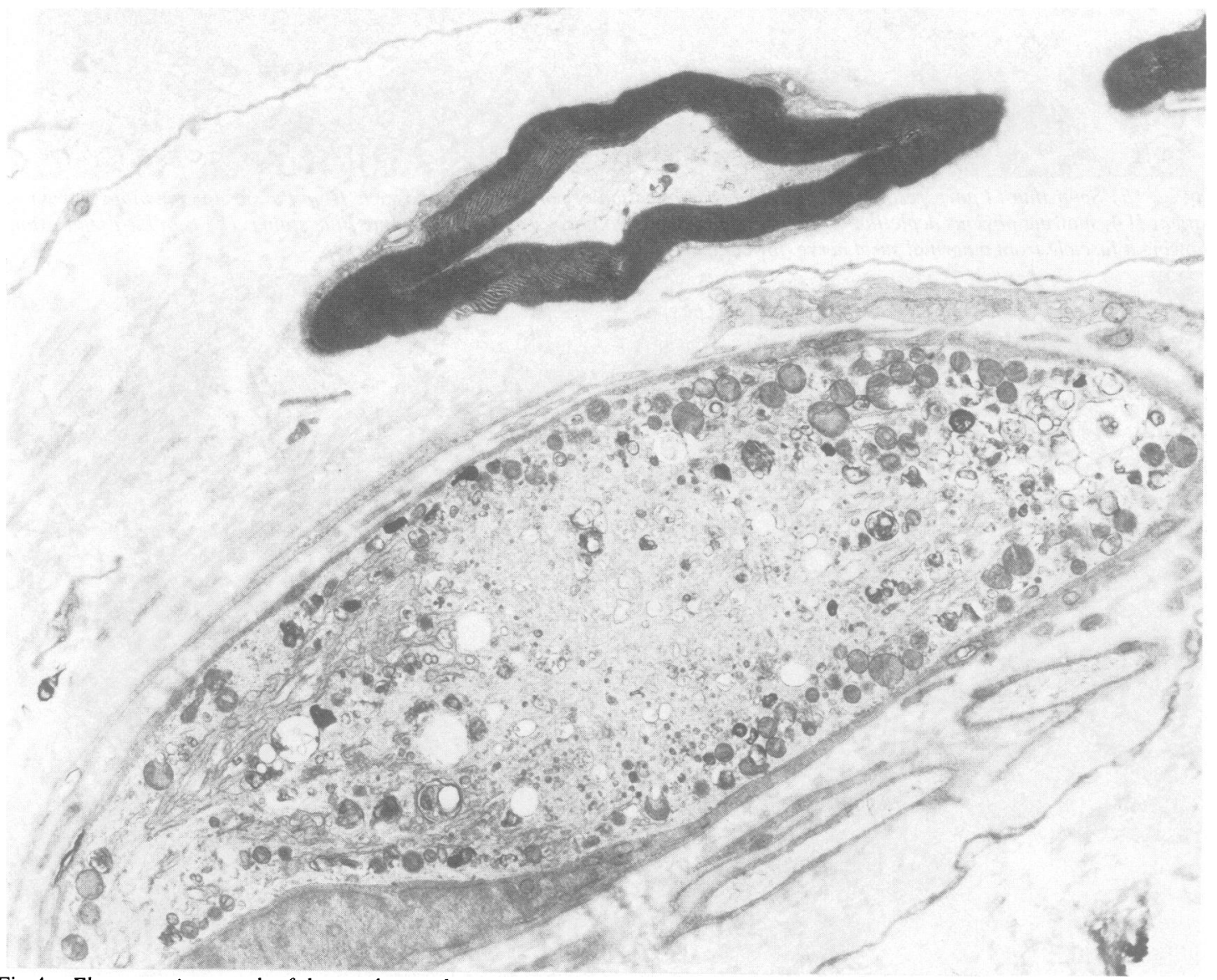

Fig 4 Electron micrograph of the sural nerve biopsy specimen (case 2), showing a degenerate axon swelling with abnormal accumulation of neurofilaments and other organelles. $\times 8700$. 


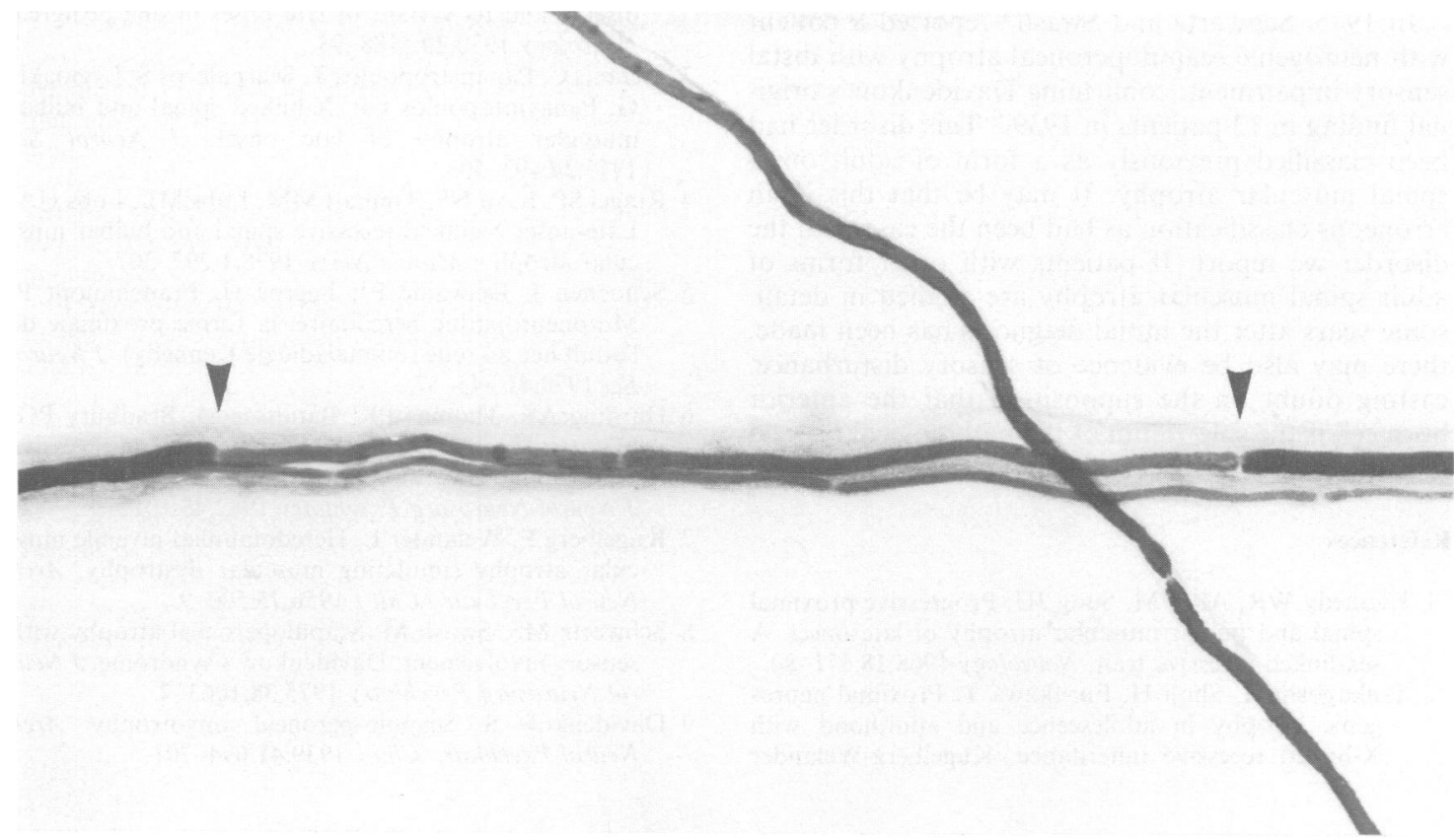

Fig 5 Teased fibre preparation from the sural nerve biopsy specimen (case 2), showing evidence of segmental demyelination. One nerve fibre present shows replacement of a complete internode by two, shorter, thinly remyelinated segments (arrows). $\times$ 200.

\section{Discussion}

In 1956, Kugelberg and Welander ${ }^{7}$ described a recessively inherited disorder characterised by slowly progressive proximal muscular wasting and weakness starting in childhood which resulted from chronic degeneration of anterior horn cells. Since then numerous different forms of spinal muscular atrophy have been described with variation in age of onset, pattern of predominant muscle involvement and mode of inheritance, one such form being reported by Kennedy and colleagues. ${ }^{1}$ The findings of Harding and colleagues ${ }^{6}$ of sensory nerve involvement in patients with this disorder suggest that it is not simply a primary degeneration of the anterior horn cell. They thus renamed the disorder as it was no longer feasible to classify it as a form of spinal muscular atrophy.

We have reported three patients, two of whom had previously been erroneously classified as having spinal muscular atrophy, with $\mathrm{X}$-linked recessive bulbospinal neuronopathy, to draw further attention to its existence as a distinct entity because of the importance of its genetic implications. Its clinical features make it a well-defined condition and if clinicians are aware of its existence the diagnosis should be easily made.

In an X-linked recessive disorder, there is a high chance of males developing the condition in isolation with a negative family history. It is probable that many cases of bulbo-spinal neuronopathy have been included erroneously in case reports of other adult onset spinal muscular atrophies or motor neuron disease because this specific disease entity and inheritance pattern has not been recognised.

All daughters of patients with this disorder will be obligate carriers and will have a $50 \%$ chance of transmitting it to their male offspring. As yet there is no way of identifying female carriers. Table 1 shows the average of three blood samples from both obligate and possible carriers. Only one obligate carrier has an elevated creatine kinase level, although III 10, the daughter of an obligate carrier, had a level at the upper limit of normal suggesting that she may be a carrier, but we suspect that creatine kinase levels will not be of value in identifying possible carriers, a conclusion shared by Ringel and colleagues. ${ }^{4}$

We have confirmed the findings of Harding and colleagues of the involvement of sensory pathways in this disorder. The sural nerve histology showed evidence of axonal degeneration and segmental demyelination, together with marked endoneural fibrosis, these features being indicative of a chronic neuropathy. We think it probable that the symptoms and signs result from a dying-back process due to a primary disorder affecting the anterior horn and dorsal root ganglion cells. 
In 1975, Schwartz and Swash ${ }^{8}$ reported a patient with neurogenic scapuloperoneal atrophy with distal sensory impairment, confirming Davidenkow's original finding in 13 patients in $1939 .{ }^{9}$ This disorder had been classified previously as a form of adult onset spinal muscular atrophy. It may be that this is an erroneous classification as had been the case with the disorder we report. If patients with other forms of adult spinal muscular atrophy are studied in detail, some years after the initial diagnosis has been made, there may also be evidence of sensory disturbance, casting doubt on the supposition that the anterior horn cell is the sole victim of the pathological process in this group of disorders.

\section{References}

1 Kennedy WR, Alter M, Sung JH. Progressive proximal spinal and bulbar muscular atrophy of late onset. A sex-linked recessive trait. Neurology 1968;18:671-80.

2 Tsukagoshi H, Shoji H, Furukawa T. Proximal neurogenic atrophy in adolescence and adulthood with $\mathrm{X}$-linked recessive inheritance. Kugelberg-Welander disease and its variant of late onset in one pedigree. Neurology 1970;20:1188-93.

3 Stefanis C, Papapetropoulos T, Scarpalezos S, Lygidakis G, Panayiotopoulos CP. X-linked spinal and bulbar muscular atrophy of late onset. $J$ Neurol Sci 1975;24:493-503.

4 Ringel SP, Lava NS, Treihaft MM, Lubs ML, Lubs HA. Late-onset X-linked recessive spinal and bulbar muscular atrophy. Muscle Nerve 1978;1:297-307.

5 Schoenen J, Delwaide PJ, Legros JJ, Franchimont P. Motoneuropathie hereditaire: la forme proximale de l'adult liée au sène (ou maladie de Kennedy). $J$ Neurol Sci 1979;41:343-57.

6 Harding AE, Thomas PK, Baraitser M, Bradbury PG, Morgan-Hughes JA, Ponsford JR. X-linked recessive bulbo-spinal neuronopathy: a report of ten cases. J Neurol Neurosurg Psychiatry 1982;45:1012-9.

7 Kugelberg E, Welander L. Heredofamilial juvenile muscular atrophy simulating muscular dystrophy. Arch Neurol Psychiatr (Chic) 1956;75:500-9.

8 Schwartz MS, Swash M. Scapuloperoneal atrophy with sensory involvement: Davidenkow's syndrome. J Neurol Neurosurg Psychiatry 1975;38:1063-7.

9 Davidenkow S. Scapulo-peroneal amyotrophy. Arch Neurol Psychiatr (Chic) 1939;41:694-701. 